\title{
Critical Assessment of Temperature Distribution in Submerged Arc Welding Process
}

\author{
Vineet Negi and Somnath Chattopadhyaya \\ Department of ME\&MME, ISM, Dhanbad 826004, India \\ Correspondence should be addressed to Vineet Negi; negi.vineet@ismu.ac.in
}

Received 31 May 2013; Accepted 27 August 2013

Academic Editor: S. Miyazaki

Copyright ( 2013 V. Negi and S. Chattopadhyaya. This is an open access article distributed under the Creative Commons Attribution License, which permits unrestricted use, distribution, and reproduction in any medium, provided the original work is properly cited.

\begin{abstract}
Temperature distribution during any welding process holds the key for understanding and predicting several important welding attributes like heat affected zone, microstructure of the weld, residual stress, and distortion during welding. The accuracy of the analytical approaches for modeling temperature distribution during welding has been constrained by oversimplified assumptions regarding boundary conditions and material properties. In this paper, an attempt has been made to model the temperature distribution during submerged arc welding process using finite element modeling technique implemented in ANSYS v12. In the present analysis, heat source is assumed to be double-ellipsoidal with Gaussian volumetric heat generation. Furthermore, variation of material properties with temperature and both convective and radiant heat loss boundary condition have been considered. The predicted temperature distribution is then validated against the experimental results obtained by thermal imaging of the welded plate, and they are found to be in a good agreement.
\end{abstract}

\section{Introduction}

Submerged arc welding (SAW) process is a widely used welding process in the industry for welding of thick plates, particularly steel. SAW is essentially an automatic or semiautomatic process with consumable electrode being continuously fed from a wire electrode roll. The process involves generation of heat by an arc produced between the consumable wire electrode and the work piece. The arc so produced is covered in a mass of fusible granular flux. The flux aids the process in many ways: it forms a protective coating over the weld, removes impurities form the weld in the form of slag, shapes the weld bead, and influences the chemical composition of the weld and its mechanical properties. Since the arc as well as the weld pool is covered by a layer of granulated flux, the loss of heat energy is considerably reduced. This makes SAW one of the most efficient welding processes with arc efficiencies reaching as high as $0.84 \pm 0.03$ [1]. The diameter of the consumable electrode ranges from 1 to $5 \mathrm{~mm}$. A constantpotential DC power source, which allows the arc length control by self-adjusting effect, is generally used with thin wires (up to $2.4 \mathrm{~mm}$ ). For wires having higher diameter, constant current DC source is used. However, at very high welding currents, AC is preferred in order to minimize arc blow [2]. Owing to the higher heat generation in this process, high welding speeds up to $5 \mathrm{~m} / \mathrm{min}$ are attainable. Higher heat generation and rapid welding considerably reduce distortion during welding, which occurs due to the expansion and contraction of the weld adjacent base metal [3].

Analysis of temperature distribution during welding is important because temperature distribution has a significant influence on residual stress, distortion, and hence, the fatigue behavior of weld structure [4]. This problem, a transient heat transfer type, essentially involves consideration for the type of heat source, temperature dependent material properties, effect of latent heat, heat of phase transformation, plate geometry, and convection and surface depression in weld pool, and convective and radiant heat loss at boundaries [5]. Over the years, several attempts have been made to solve this problem by making various assumptions regarding the aforementioned factors. Rosenthal formulated an analytical solution to transient temperature field in a semi-infinite body subjected to an instant point heat source, line heat source, or surface heat source [6]. Christensen et al's work showed a good 
agreement between Rosenthal's point heat-source based solution and actual weld bead geometry, under a wide range of welding conditions and material properties, over several orders of magnitude. However, the work also reported experimental scatter ranging up to a factor of three [7]. Rykalin and Nikolaev and Lin stressed on the need to consider nonconstant thermal properties, heat of phase transformation, heat input magnitude and distribution, convection and surface depression in weld pool in transient heat flow model to improve its accuracy $[8,9]$. Grosh and Trabant showed that the effect of nonconstant thermal properties can only contribute about 10-15 percent error observed in weld pool geometry [10]. The effect of latent heat has also been shown to produce only 5-10 percent error in prediction of weld geometry [5]. This clearly highlighted the importance of other factors, besides latent heat and nonconstant thermal properties, in contributing to the scatter observed in Christensen's experiments. Investigations into the actual heat intensity distribution in arcs on a water-cooled copper anode made it possible to determine the effect of distributed heat source on the weld geometry [11]. This solution retained all the assumptions in Rosenthal's analysis, including absence of convection in weld pool, variation of material properties, and latent heat of phase transformation, except the assumption to consider arc as a point heat source. Rosenthal's solutions can satisfactorily predict temperature field only in the region far from the weld pool. However, solutions considering arc as a distributed heat source were able to eliminate much of the experimental deviations in close vicinity of weld pool. Eagar and Tsai modified Rosenthal's solution to include a two-dimensional (2-D) surface Gaussian distributed heat source with a constant distribution parameter (which can be considered as an effective solution of arc radius) and found an analytical solution for the temperature of a semi-infinite body subjected to this moving heat source [12]. Although the 2-D Gaussian heat distribution was able to reduce the experimental scatter, it still could not include weld penetration into the picture. A more generalized formulation of heat source was much required. Goldak et al. first introduced a 3-dimensional double ellipsoidal moving heat source. A finite element analysis was performed using the double ellipsoidal heat source, and it was found to be accurate in predicting temperature distribution in welds having deeper penetration [13]. Subsequently, both analytical and numerical solutions have been formulated using this heat source to predict temperature distribution in various welding processes [14]. However, same assumptions except about the heat source still applied to the analytical solutions, thus constraining their accuracy. In this paper, numerical solution using finite element approach has been applied to model transient temperature field in SAW process. Unlike the analytical approach, assumptions regarding constant material properties, semi-infinite plate geometry, and no heat losses at boundary have been eliminated for realistic simulation of transient temperature field in SAW process.

\section{Mathematical Modeling of Heat Source}

In the initially proposed ellipsoidal heat source, the volumetric heat generation is distributed in a Gaussian manner

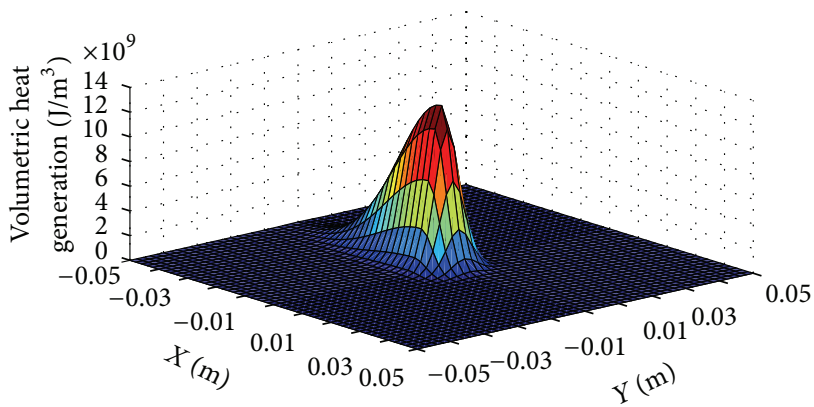

FIGURE 1: Double ellipsoidal heat source.

throughout the welding region. A major problem associated with this type of heat source is that it tends to provide a less steep temperature gradient ahead of the arc and steeper gradient behind the arc than what was experimentally observed. The above problem was solved by a double ellipsoidal heat source which consists of a combination of two different semiellipsoidal heat source volumes as shown in Figure 1. The spread of the front semiellipsoid along the weld direction is roughly four times the spread of the back semiellipsoid. A double ellipsoid is specified by four parameters, namely, $a_{f}, a_{b}, b$, and $c$. Values of these parameters can be obtained from the measurement of the weld pool geometry, that is, weld bead width and weld penetration [14]. Consider the following:

$$
\begin{aligned}
& Q(x, y, z, t) \\
& \quad= \begin{cases}\frac{2 \sqrt{a_{b} b c}}{\pi^{3 / 2}} Q_{0} f_{b} e^{-\left[a_{b}(x-v t)^{2}+b y^{2}+c z^{2}\right]}, & x-v t<0, \\
\frac{2 \sqrt{a_{f} b c}}{\pi^{3 / 2}} Q_{0} f_{f} e^{-\left[a_{f}(x-v t)^{2}+b y^{2}+c z^{2}\right]}, & x-v t \geq 0,\end{cases}
\end{aligned}
$$

where $Q$ is the volumetric heat generation at a point, $Q_{0}$ is net heat input in the process, $x, y$, and $z$ are the coordinates measured from starting point of the welding process; $v$ and $t$ are welding speed and time elapsed, respectively, $f_{f}$ and $f_{b}$ are proportion coefficients representing heat appointment in front and back of the heat source. Their values can be found by equating the heat generated from the front and rear semiellipsoid at their interface in the middle. Consider the following:

$$
f_{f}=\frac{2 \sqrt{a_{b}}}{\sqrt{a_{f}}+\sqrt{a_{b}}}, \quad f_{b}=\frac{2 \sqrt{a_{f}}}{\sqrt{a_{f}}+\sqrt{a_{b}}} .
$$

The value of the parameters $a_{f}, a_{b}, b$, and $c$ can be found by assuming the volumetric heat generation at the boundary between the weld pool and the base material of about $0.05 Q(0)[13]$.

In forward $x$-direction,

$$
Q\left(A_{f}, 0,0\right)=Q(0) e^{-\left(a_{f} A_{f}^{2}\right)}=0.05 Q(0) .
$$

Hence,

$$
a_{f}=\frac{\ln 20}{A_{f}^{2}} \cong \frac{3}{A_{f}^{2}}
$$


Similarly,

$$
a_{b} \cong \frac{3}{A_{b}^{2}}, \quad b \cong \frac{3}{B^{2}}, \quad c \cong \frac{3}{C^{2}},
$$

where $B$ is half of weld bead width; $C$ is weld penetration; $A_{f}$, and $A_{b}$ are the semiaxes in forward and backward $x$ direction, respectively, $A_{f}$ can be assumed as one-half of the weld width, and $A_{b}$ as twice the weld width [13].

\section{Finite Element Modeling}

3.1. Material Properties. As mentioned earlier, the analytical method to model temperature distribution during welding assumes the material properties to be constant. However, in the present analysis, the variation of material properties as well as the effect of phase transformation and weld pool convection is given due consideration. The material properties required in the preprocessing step of finite element analysis are density, thermal conductivity, and specific heat capacity of steel. It is difficult to obtain accurate temperature dependent material properties data from the literature. Hence, a basic assumption that the material property does not vary much with only a slight variation in composition of the material has been made while obtaining the material properties data. The density of low carbon steel or structural steel is taken as $7850 \mathrm{~kg} / \mathrm{m}^{3}$, and it is assumed to remain constant throughout the process. The same, however, cannot be said about conductivity and specific heat capacity.
3.1.1. Conductivity. Conductivity of low carbon steel varies considerably with temperature. Thermal conductivity of low carbon steel is about $53 \mathrm{~W} / \mathrm{mK}$ at room temperature and shows an almost linear reduction with temperature to a value of $27 \mathrm{~W} / \mathrm{mK}$ at approximately $800^{\circ} \mathrm{C}$ [15].

Weld pool convection increases the heat transfer in the molten weld pool due to its stirring effect. Since the experimental measurement as well as the simulation of the weld pool convection is an extremely complex task, the effect of weld pool convection is approximated by increasing the conductivity of the metal beyond the liquidus temperature by a multiple, which is usually between eight and ten [16]. Goldak et al. (1984) suggested the use of a fictitious value of thermal conductivity of $120 \mathrm{~W} / \mathrm{mK}$ to account for the enhancement in heat transfer in the liquid zone due to weld pool convection [13]. In this paper, same approach as that of Goldak et al. (1984) has been adopted, and the thermal conductivity of low carbon steel has been artificially set to $120 \mathrm{~W} / \mathrm{mK}$ in the liquidus region. Figure 2 shows the variation of the conductivity with consideration of weld pool convection.

3.1.2. Specific Heat. Specific heat is defined as heat energy absorbed by a unit mass of a material to raise its temperature by $1 \mathrm{~K}$. Like conductivity, specific heat of low carbon steel also varies with temperature. Latent heat of phase transformation also affects the specific heat of the material near the vicinity of phase transformation. The first phase transformation in low carbon steel occurs as ferritic structure changes to austenitic crystalline structure at about $723^{\circ} \mathrm{C}$. This increases the specific heat capacity at phase transformation temperature $\left(723^{\circ} \mathrm{C}\right)$. Consider the following:

$$
C_{a}= \begin{cases}425+7.73 \times 10^{-1} T_{a}-1.69 \times 10^{-3} T_{a}^{2}+2.22 \times 10^{-6} T_{a}^{3}, & 20^{\circ} \mathrm{C} \leq T_{a}<600^{\circ} \mathrm{C} \\ 666+\frac{13002}{738-T_{a}}, & 600^{\circ} \mathrm{C} \leq T_{a}<735^{\circ} \mathrm{C} \\ 545+\frac{17820}{T_{a}-731}, & 735^{\circ} \mathrm{C} \leq T_{a}<900^{\circ} \mathrm{C} \\ 650, & 900^{\circ} \mathrm{C} \leq T_{a} \leq 1200^{\circ} \mathrm{C}\end{cases}
$$

The above variation (Eurocode 3-EN 1993-1-2 (2005) specifications [17]) is not feasible to be used directly in the FEA model as it will make the system highly nonlinear and will increase the processing time tremendously. A compromise was made by taking a linear approximation of the graph segments to prevent the model from becoming unwieldy.

Another phase transformation occurs at solidus-liquidus phase change, which has a latent heat of about $260 \mathrm{KJ} / \mathrm{Kg}$. However, some researchers suggest that latent heat of fusion has insignificant effect on temperature distribution [18]. Nonetheless, in this paper, the effect of latent heat of fusion has been considered. The release of latent heat has been assumed to be uniformly distributed between the solidus and the liquidus temperatures. The effect of latent heat can be incorporated in the model by artificially increasing the specific heat capacity of low carbon steel in the solid-liquid phase transformation region [19]. The overall variation of specific heat with temperature is shown in Figure 3.

3.2. Boundary Condition. Heat losses in the welding process take place by both convection and radiation. The radiation heat loss being proportional to the fourth power of temperature becomes prominent only at higher temperature, which is encountered in the close vicinity of the weld pool. As opposed to the radiation heat loss, convective heat loss becomes a primary mechanism of heat loss at low temperature region away from the weld line. Some researchers prefer using a single heat loss equation to model both processes proposed by Vinokurov (7) [20,21].

Consider

$$
h_{\text {comb }}=24.1 \times 10^{-4} E T_{b}^{1.61},
$$




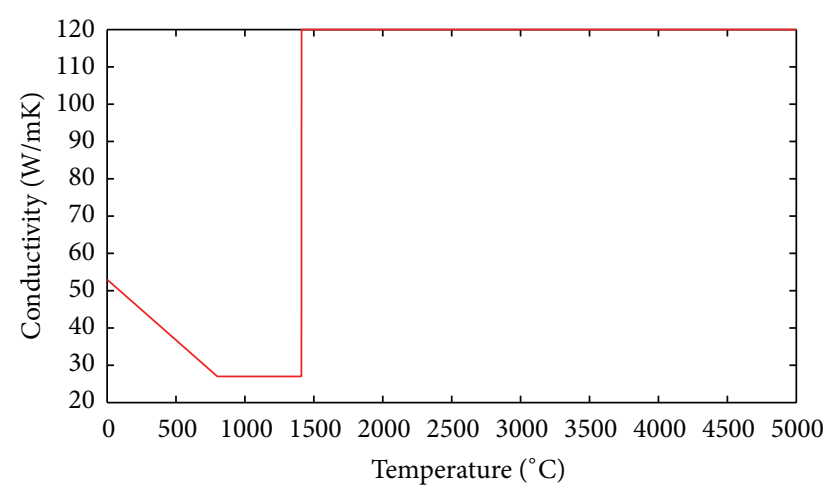

FIGURE 2: Variation of conductivity with temperature plot.

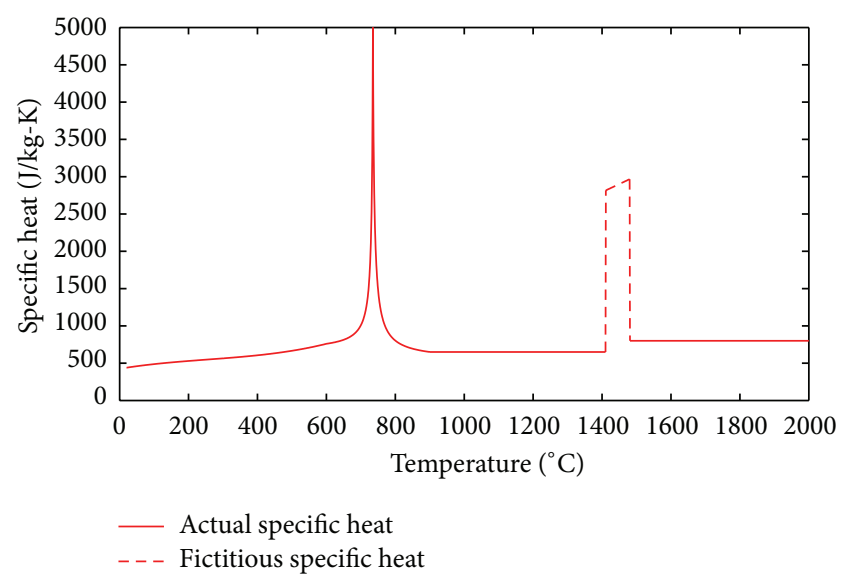

FIgURE 3: Apparent variation of specific heat with temperature.

where $h_{\text {comb }}$ is combined heat transfer coefficient, $E$ is emissivity of material, and $T_{b}$ is temperature of the body. This equation was, however, reported inaccurate by Goldak as compared to applying Newton's law of cooling and Stefan Boltzmann law of radiation separately. Therefore, in this analysis, the radiant heat loss and the convective heat loss have been applied separately.

In submerged arc welding process, the granular flux covers the weld region completely thereby providing insulation to it. This results in a more gradual decrease in temperature of the welded zone. Since the flux covers the maximum part of the plate $(20 \mathrm{~cm} \times 20 \mathrm{~cm} \times 1.5 \mathrm{~cm})$ used in the experiment, the top face of the plates has been assumed to be insulated; that is, convection and radiation heat losses are ignored in the upper face of the plate. This assumption is valid only for submerged arc welding process and distinguishes it from other welding processes which use an inert gas for shielding the arc like TIG and MIG.

3.3. Meshing and Time-Stepping. A finite element model of the submerged arc welding process was created using ANSYS v12.0. The accuracy of a model depends upon its element size or number of nodes and time step size. The increase in number of nodes not only increases the accuracy of the model, but it also increases the processing time of the model.

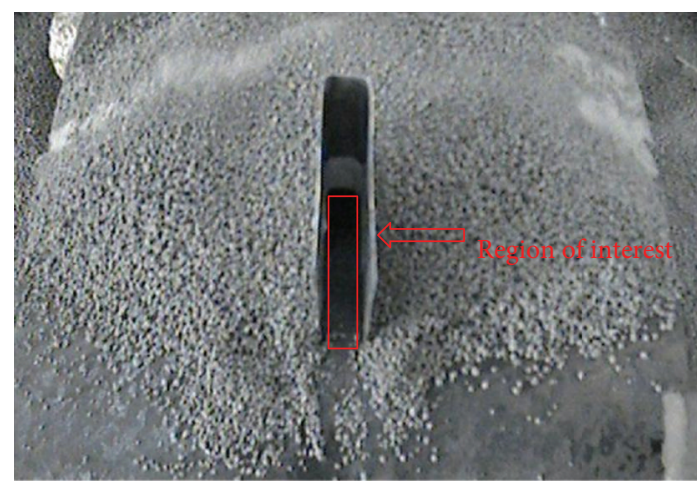

FIGURE 4: Location and function of the U-piece along with region of interest on the welded plate.

An optimum solution could be reached by increasing node density near the region of high temperature gradient, which is in the vicinity of weld line, and decreasing node density near the region of low temperature gradient, which is away from the weld line. Also, automatic time stepping, which aims at reducing the processing time of the solution especially of nonlinear and transient dynamic problems by automatically estimating the next time step based on the present state of the system and the previous processing step, has been applied.

\section{Experimental Procedure}

For validation of numerical solution, temperature variation, both temporal and spatial, has to be determined experimentally. In the present work, infrared thermography has been used to determine the temperature profile of the plate at various time steps, thereby capturing both temporal and spatial variation of temperature. In submerged arc welding process, the molten weld metal is covered by an envelope of molten flux and a layer of unfused flux [22]. The granular flux provides insulation to the weld and makes the thermal imaging of the region infeasible. Even the sides of the weld are covered by stray flux particles, thus interfering with the measurement of temperature by IR camera [23]. This necessitates the use of a method to remove this flux, thereby eliminating any interference in thermal imaging, for example, a vacuum flux remover provided just behind the welding torch head [23]. In the present work, a $(13 \mathrm{~cm} \times 5 \mathrm{~cm})$ piece of sheet metal was bent in a U-shape having a gap of about $1 \mathrm{~cm}$ between the two arms. A layer of insulation was provided at the bottom of the U-shaped sheet metal to minimize the heat transfer coefficient at the bottom. This U-shaped sheet metal with closed end facing the weld line was inserted into the flux covered region at the middle of the weld line from the side as shown in Figure 4. The U-piece cleared the flux from that zone and provided a window (region of interest (ROI)) to measure the temperature profile of the region without much altering the profile itself. This was because the uncovered region was much smaller as compared to the covered region; therefore, the convection and radiation heat loss from the uncovered region could not much affect the temperature profile of the plate. Also, the negligible area of 
TABLE 1: Experimental data.

\begin{tabular}{lccccc}
\hline Current $(\mathrm{A})$ & Voltage $(\mathrm{V})$ & Average speed $(\mathrm{cm} / \mathrm{min})$ & Weld width $(\mathrm{mm})$ & Weld depth $(\mathrm{mm})$ & Average MDR $(\mathrm{Kg} / \mathrm{min})$ \\
\hline 400 & 30 & 39.52 & 14.60 & 7.20 & 0.08 \\
\hline
\end{tabular}

$\gg 274.61^{\circ} \mathrm{C}$
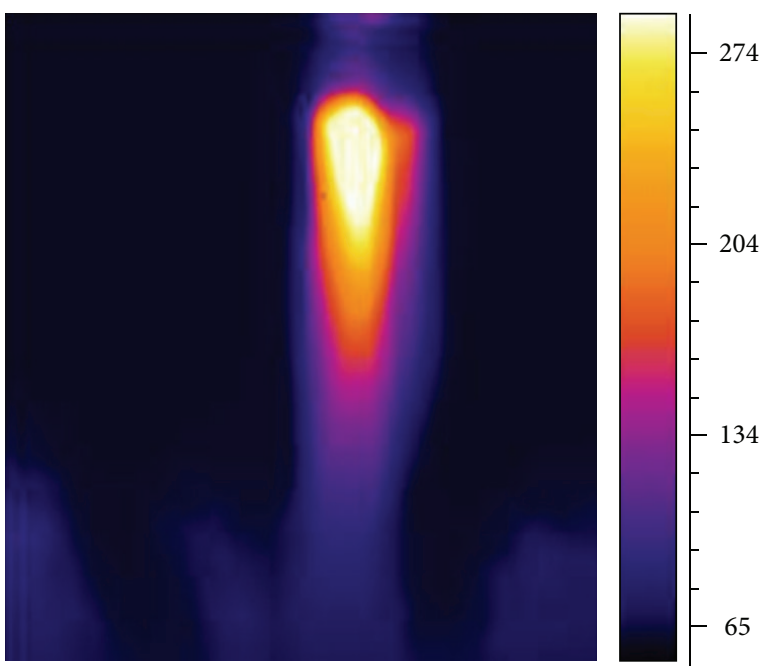

$\ll 37.98^{\circ} \mathrm{C}$

IR_17

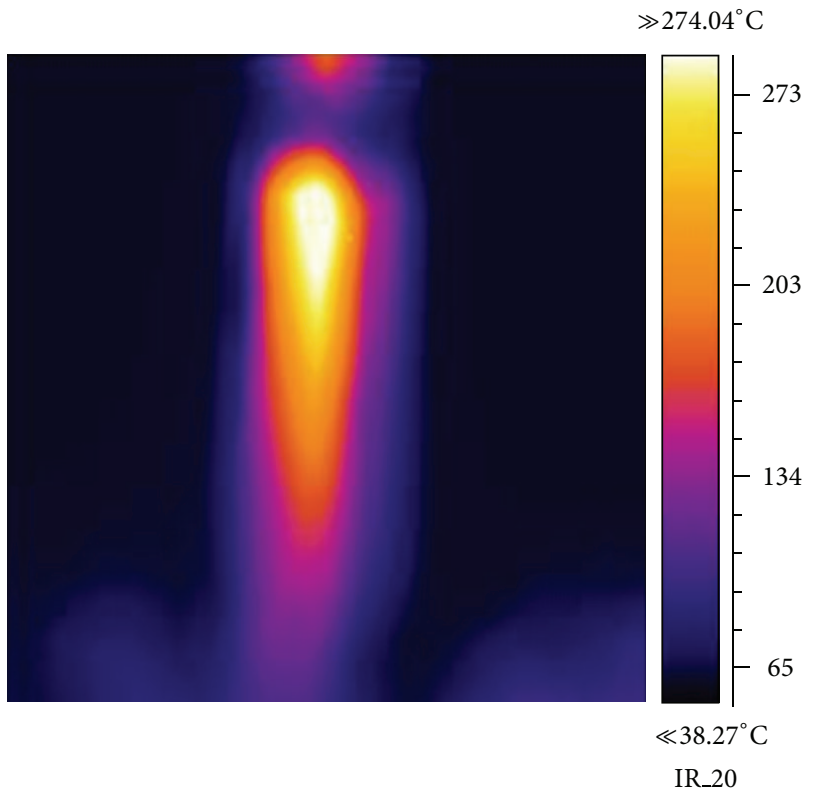

Figure 6: Thermal image of the ROI at $t=85 \mathrm{sec}$.

contact between the U-shaped sheet metal and the plate in addition to the insulation provided at the bottom of U-piece ensured minimum heat transfer to the sheet metal, while it was in contact with the weld plate.

A structural steel plate of dimension $(200 \mathrm{~mm} \times 200 \mathrm{~mm}$ $\times 15 \mathrm{~mm}$ ) was cut into two equal parts. A V-groove of $60^{\circ}$

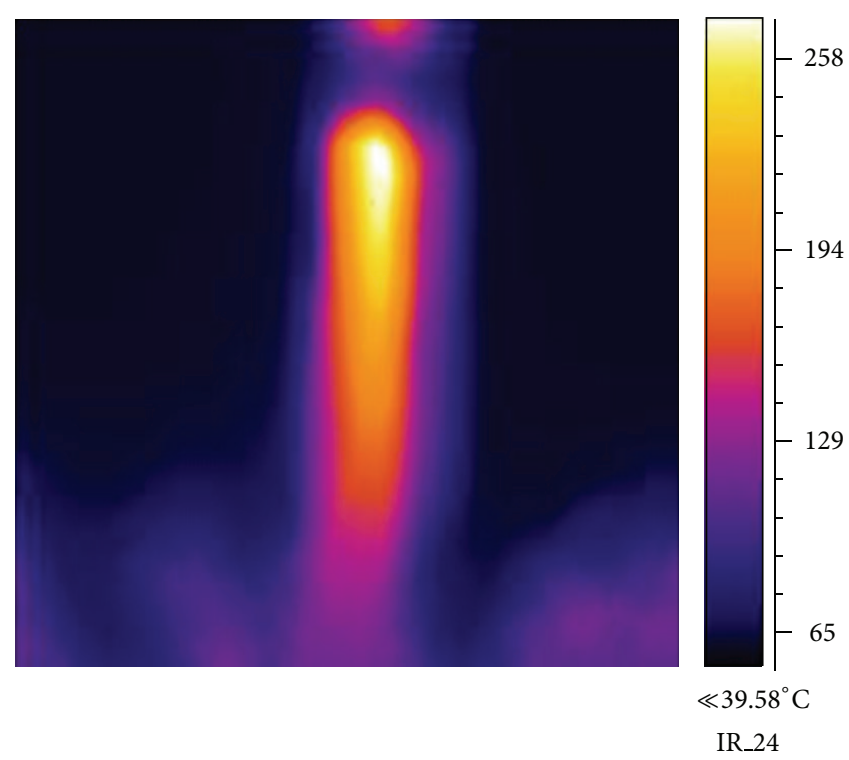

FIGURE 7: Thermal image of the ROI at $t=115 \mathrm{sec}$.

angle was prepared as per standards. The plates were joined preliminarily by tack welding at three points, and welding was performed on MEMCO semiautomatic welding equipment with a constant voltage rectifier. The flux used was ADOR Auto melt Gr II AWS/SFA 5.17 Granular, and the electrode used was ADOR 3.15 diameter copper coated wire. The welding parameters were noted during the actual welding process for any fluctuations. The U-shaped sheet metal was inserted at the middle as shown in Figure 4, and thermal images of the region of interest (ROI) were taken using an IR camera (RayCam C.A. 1888) at a regular interval of $10 \mathrm{sec}$ from $55 \mathrm{sec}$ to $265 \mathrm{sec}$. The welded plate was then allowed to cool, flux was removed using a chipping hammer, and width and penetration of the weld bead were measured (see Table 1).

\section{Analysis and Results}

The 3D finite element analysis was performed in ANSYS v12.0, and temperature at specific instances of time was extracted for the whole plate. To determine the temperature in the region of interest (ROI) from the FEA model, the temperature was mapped along the path defined by the line perpendicular to the weld line on the upper face of the plate and intersecting it at its middle. The pseudocolor thermal image of ROI was converted to gray-scale image, and the intensity value along the middle line was extracted by using Matlab code.

These values were then scaled to give the actual temperature profile along the contour. The predicted temperature 


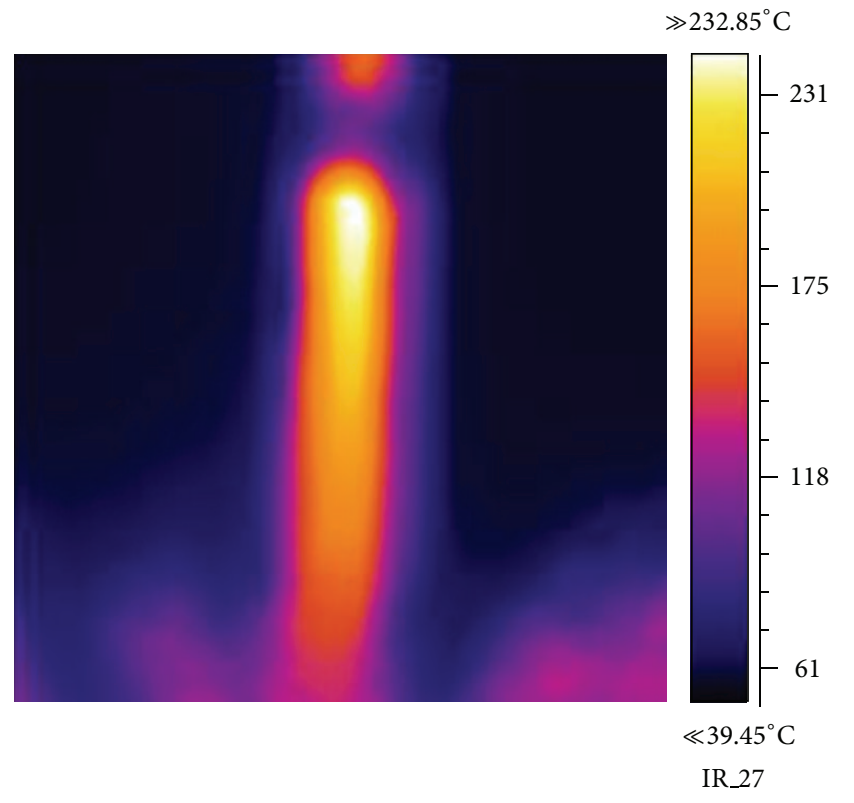

FIGURE 8: Thermal image of the ROI at $t=145 \mathrm{sec}$.

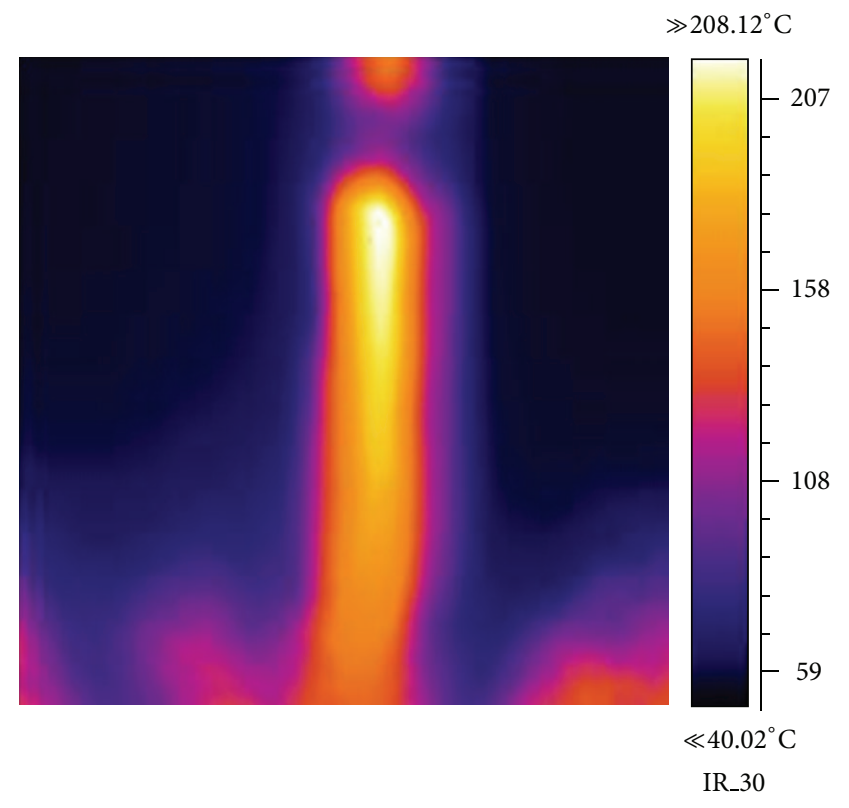

FIgURE 9: Thermal image of the ROI at $t=175 \mathrm{sec}$.

profile obtained from ANSYS simulation was plotted with the temperature profile obtained experimentally for comparison.

The graphs of temperature variation along midline for various instances, Figures 10, 11, 12, 13, and 14, as well as the thermal images of region of interest (ROI) at these instances, Figures 5, 6, 7, 8, and 9, clearly show a reasonably good agreement between predicted and experimental results. Moreover, $r$-square statistic and root mean square error (RMSE) value in Table 2 quantitatively establish the accuracy of prediction of FEA model. Thus, it points to the credibility

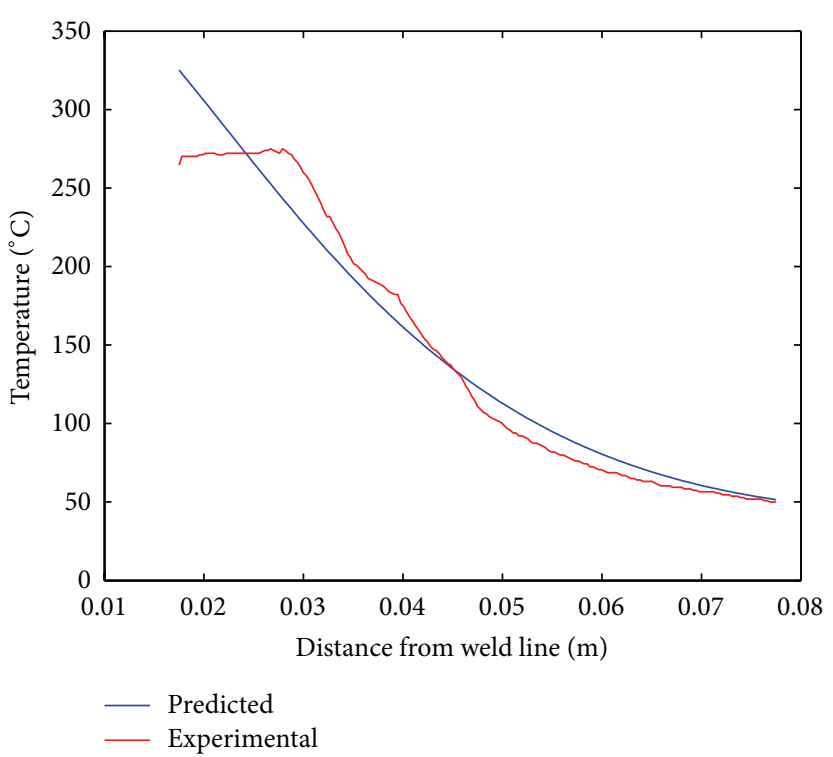

Figure 10: Temperature plot at $t=55 \mathrm{sec}$ along midline.

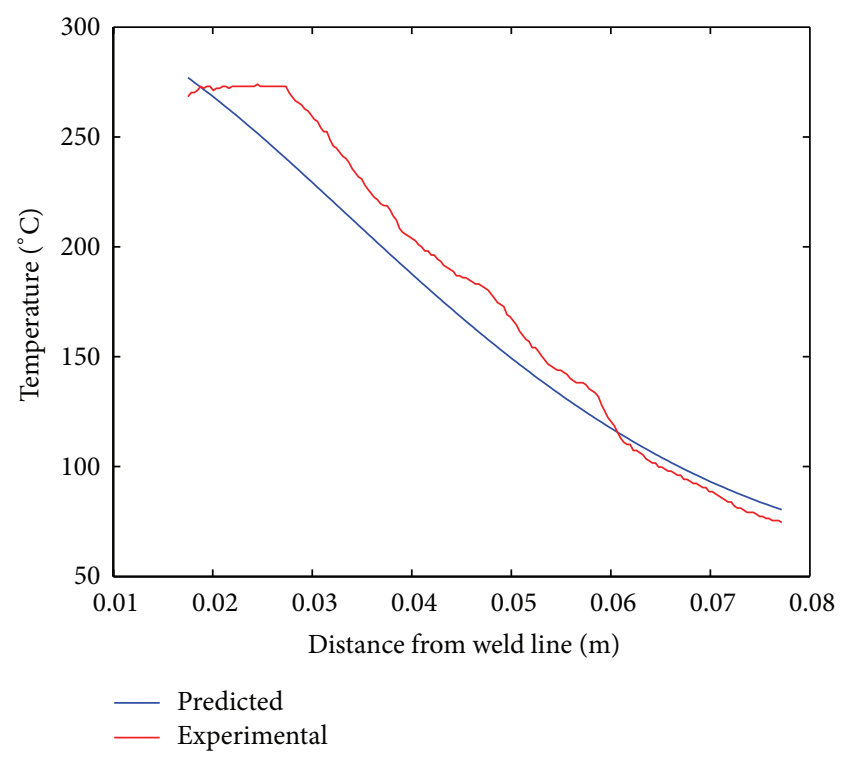

FIgURE 11: Temperature plot at $t=85 \mathrm{sec}$ along midline.

TABLE 2: Goodness of fit parameters for Figures 10-14.

\begin{tabular}{lcc}
\hline Time & \multicolumn{2}{c}{ Criteria } \\
& $R$-square & RMSE \\
\hline 55 & 0.9602 & 16.3836 \\
85 & 0.9819 & 9.3019 \\
115 & 0.9927 & 4.8237 \\
145 & 0.9929 & 3.0913 \\
175 & 0.9945 & 1.7866 \\
\hline
\end{tabular}

of finite element modeling technique in prediction of temperature variation during submerged arc welding process. The errors in the analysis arise primarily due to inaccuracies in 


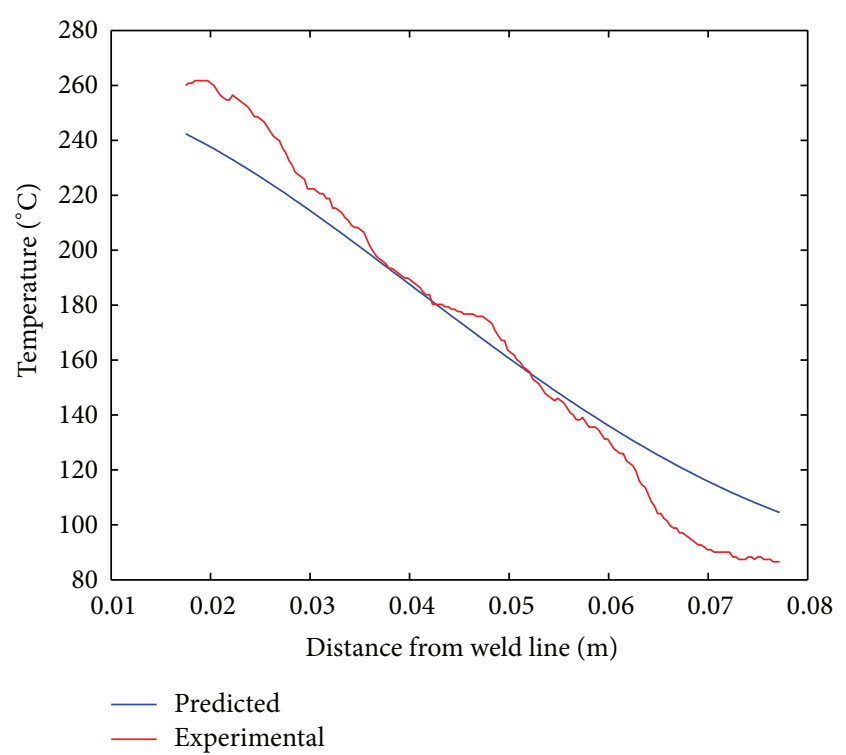

FIgURE 12: Temperature plot at $t=115 \mathrm{sec}$ along midline.

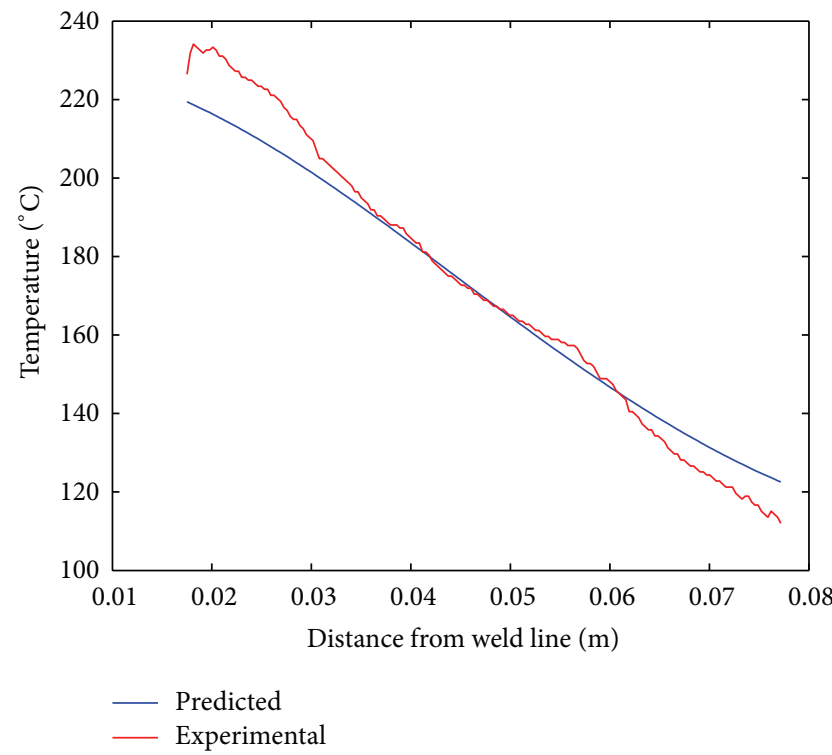

FIgURE 13: Temperature plot at $t=145 \mathrm{sec}$ along midline.

modeling of the material properties and the boundary heat loss condition. Particularly, the assumption that no heat loss due to convection or radiation occurs on the upper face, which is largely covered by stray flux particles, compromises the accuracy of the model in the outer region and at a later time as the outer bare region of the upper face gets heated enough to make the heat loss significant. The aforementioned factor can be noticed in Figures 12-14, where increased error in the region farther from weld line can be seen.

It can be observed from Figure 15 that the temperature gradient is much higher in front of the arc than at its back. Therefore, the weld region in front of the arc plays no role in heat transfer until the arc reaches there. This observation justifies the assumption of ignoring the addition of mass of the filler electrode by birth and death of the element in FEM.

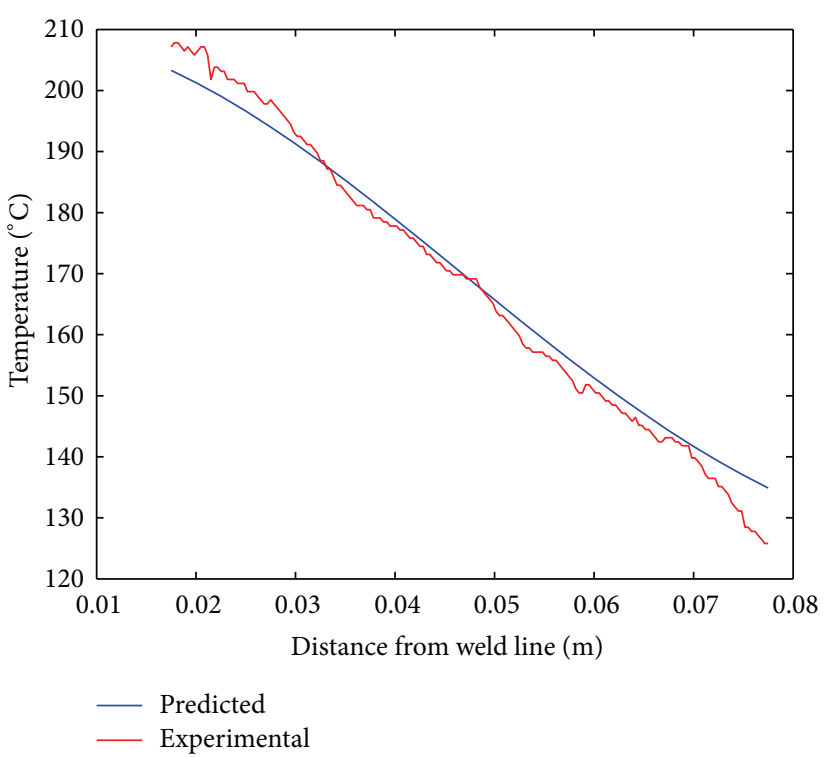

Figure 14: Temperature plot at $t=175 \mathrm{sec}$ along midline.
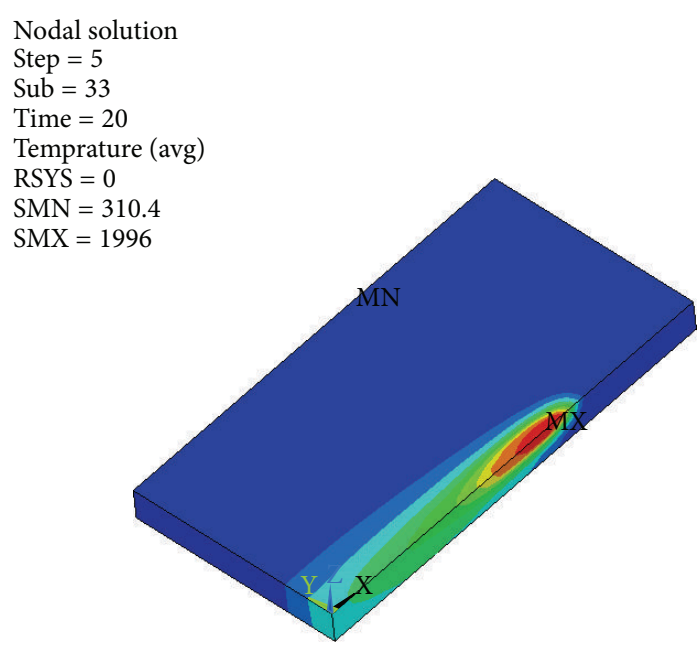

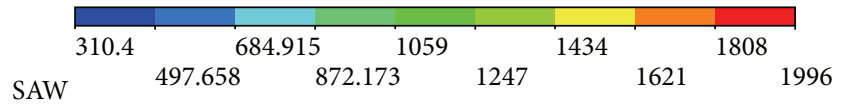

Figure 15: Temperature profile of the plate at $t=20 \mathrm{sec}$ after the start of welding (for heat input of $10200 \mathrm{~J} / \mathrm{s}$ ).

The dissipation of heat in the plate can be clearly discerned from the thermal images of the mid-region. The effect of stray flux particles in obstructing the view of IR Camera is also patent from the thermograms. Moreover, Figure 16 clearly shows the extent to which the stray flux particles shield the upper surface of the plate, thereby supporting our assumption of ignoring the heat losses from the upper face.

\section{Conclusion}

In submerged arc welding (SAW) process, the weld pool and the region around it are covered by a blanket of granular 


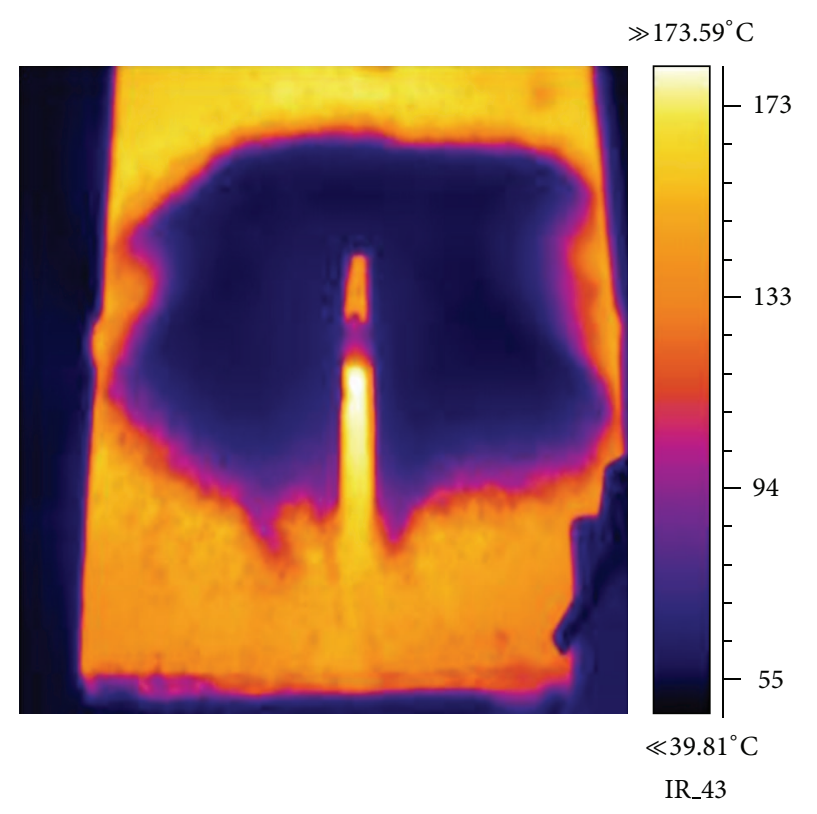

FIgURE 16: Thermogram of the upper face of the plate at time $t=$ $315 \mathrm{sec}$.

flux. This makes it infeasible to observe the temperature profile directly using either infrared thermometer or camera. Thermocouple could provide information regarding temperature at a point, but due to practical difficulties, like their interaction with the measurement, they cannot be used in sufficiently large numbers to provide spatial resolution necessary to capture temperature pattern reliably and accurately [5]. Though the experimental methodology followed in this paper allows measurement of temperature close to weld line, it still does not completely solve the problem of direct observation of the weld pool, thereby failing to analyze the performance of the FEA model closer to the weld pool. Nevertheless, the present work has validated the accuracy of FEA modeling in prediction of temperature profile sufficiently close to the weld region.

Once the credibility of FEA has been established, it opens the door to modeling and understanding a number of other properties associated with welding. The heat affected zone (HAZ) can be predicted by plotting all the points whose maximum temperature reaches more than recrystallization temperature $973 \mathrm{~K}$ but less than melting point temperature $(1683 \mathrm{~K})$ [4]. The temperature profile obtained from the transient thermal FE analysis can be used as an input loading condition for uncoupled structural analysis, which assumes that structural loads act independently of thermal loads. Similarly, the knowledge of temperature history of the plate can shed a significant insight on the microstructure of the weld region.

\section{References}

[1] J. N. DuPont and A. R. Marder, "Thermal efficiency of arc welding processes," Welding Journal, vol. 74, no. 12, pp. 406S416S, 1995.

[2] S. Kou, Welding Metallurgy, John Wiley and Sons, 2nd edition, 2003.
[3] Modern Arc Welding Technologies, Ador Welding Limited, Second edition, 2005.

[4] A. Ghosh and S. Chattopadhyaya, "Analytical solution for transient temperature distribution of semi-infinite body subjected to 3-D moving heat source of submerged arc welding process," in Proceedings of the International Conference on Mechanical and Electrical Technology (ICMET '10), pp. 733-737, September 2010.

[5] N. D. Malmuth, W. F. Hall, B. I. Davis, and C. D. Rosen, "Transient thermal phenonenon and weld geometry in GTAW," Welding Journal, vol. 53, no. 9, pp. 388S-400S, 1974.

[6] D. Rosenthal, "Mathematical theory of heat distribution during welding and cutting," Welding Journal, vol. 20, no. 5, pp. 220S234S, 1941 .

[7] N. Christensen, V. Davies, and K. Gjermundsen, "Distribution of temperature in Arc welding," British Wleding Journal, vol. 12, no. 2, pp. 54-75, 1965.

[8] N. N. Rykalin and A. V. Nikolaev, "Welding arc heat flow," Welding in the World, vol. 9, no. 3-4, pp. 112-133, 1971.

[9] M. L. Lin, Influence of Surface Depression and Convection on weld Pool Geometry [M.S. thesis], MIT, Cambridge, Mass, USA, 1982.

[10] R. J. Grosh and E. A. Trabant, "Arc Welding temperature," Welding Journal, vol. 35, no. 3, pp. 396-400, 1956.

[11] O. H. Nestor, "Heat intensity and current density distributions at the anode of high current, inert gas arcs," Journal of Applied Physics, vol. 33, no. 5, pp. 1638-1648, 1962.

[12] T. W. Eagar and N.-S. Tsai, "Temperature fields produced by traveling distributed heat sources," Welding Journal, vol. 62, no. 12, pp. 346-355, 1983.

[13] J. Goldak, A. Chakravarti, and M. Bibby, "A new finite element model for welding heat sources," Metallurgical Transactions B, vol. 15, no. 2, pp. 299-305, 1984.

[14] N. T. Nguyen, A. Ohta, K. Matsuoka, N. Suzuki, and Y. Maeda, "Analytical solutions for transient temperature of semi-infinite body subjected to 3-D moving heat sources," Welding Journal, vol. 78, no. 8, pp. 265S-274S, 1999.

[15] L. Gardner and K. T. Ng, "Temperature development in structural stainless steel sections exposed to fire," Fire Safety Journal, vol. 41, no. 3, pp. 185-203, 2006.

[16] M. Ericsson, Simulation of Robotic TIG-Welding, Department of Technology, University of Trolhattan, 2003.

[17] U. Wickstrom, "Eurocode 3. Design of steel structures.Part 1-2: general rules: structural fire design," Fire Safety Journal, vol. 40, no. 2, pp. 191-192, 2005.

[18] A. Wu, S. Syngellakis, and B. G. Mellor, "Finite element analysis of residual stresses in a Butt weld," in Proceedings of the 7th Postgraduate conference in Engineering Materials, pp. 37-38, 2003.

[19] C. K. Takemori, D. T. Muller, and M. A. de Oliveira, "Numerical simulation of transient heat transfer during welding process," in Proceedings of the International Compressor Engineering Conference, 2010.

[20] E. A. Bonifaz, "Finite element analysis of heat flow in single-pass arc welds," Welding Journal, vol. 79, no. 5, pp. 121S-125S, 2000.

[21] H. G. Fan, H. L. Tsai, and S. J. Na, "Heat transfer and fluid flow in a partially or fully penetrated weld pool in gas tungsten arc welding," International Journal of Heat and Mass Transfer, vol. 44, no. 2, pp. 417-428, 2001. 
[22] AWS Welding Handbook, vol. 2, American Welding Society, Miami, Fla, USA, 8th edition, 1991.

[23] H. C. Wikle III, S. Kottilingam, R. H. Zee, and B. A. Chin, "Infrared sensing techniques for penetration depth control of the submerged arc welding process," Journal of Materials Processing Technology, vol. 113, no. 1-3, pp. 228-233, 2001. 

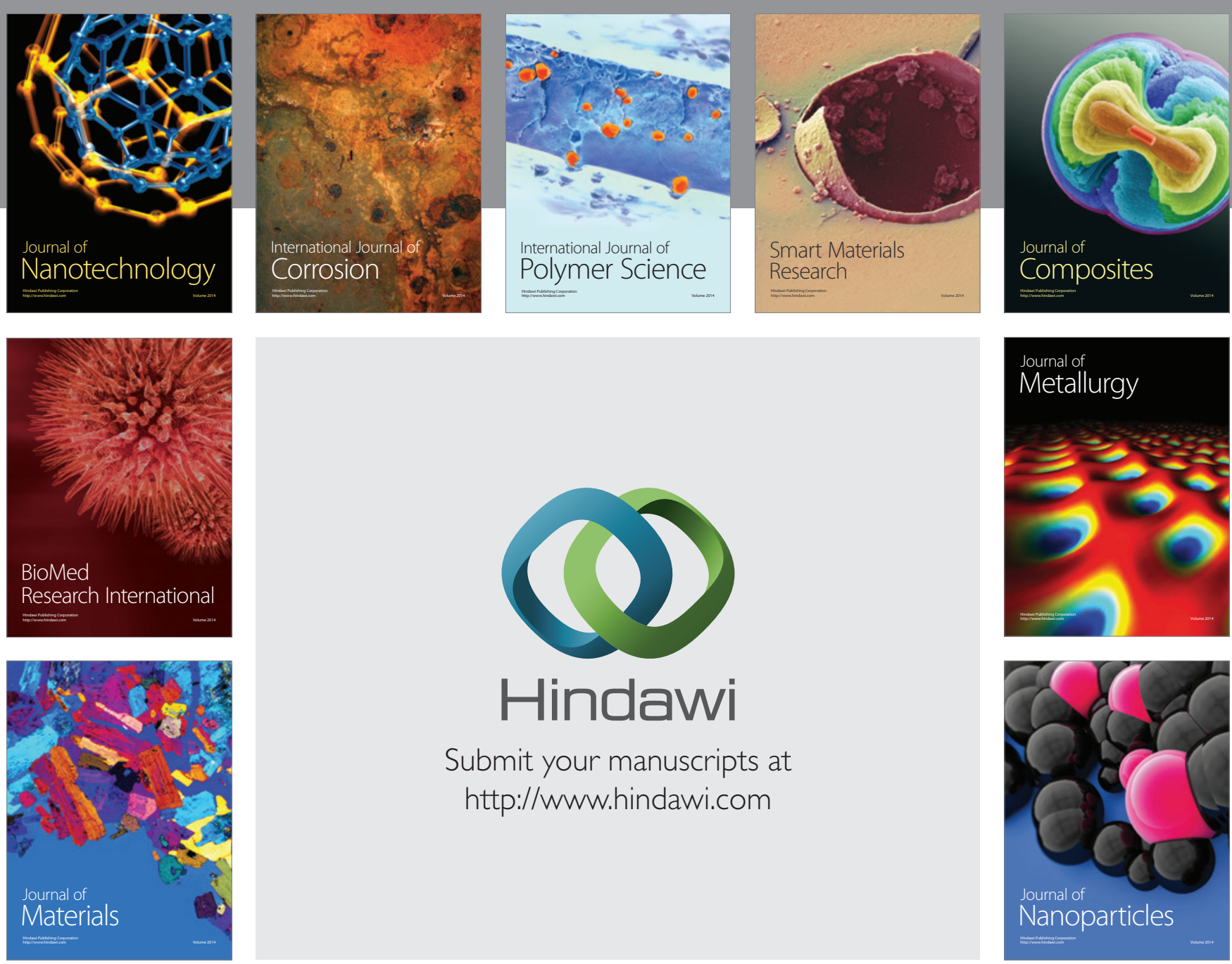

Submit your manuscripts at http://www.hindawi.com
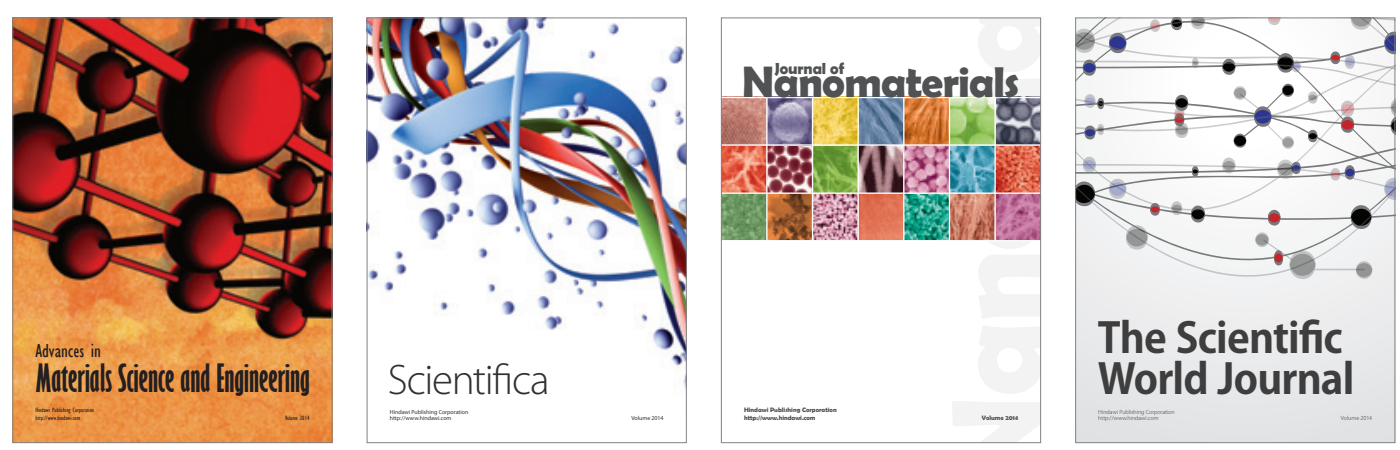

\section{The Scientific World Journal}
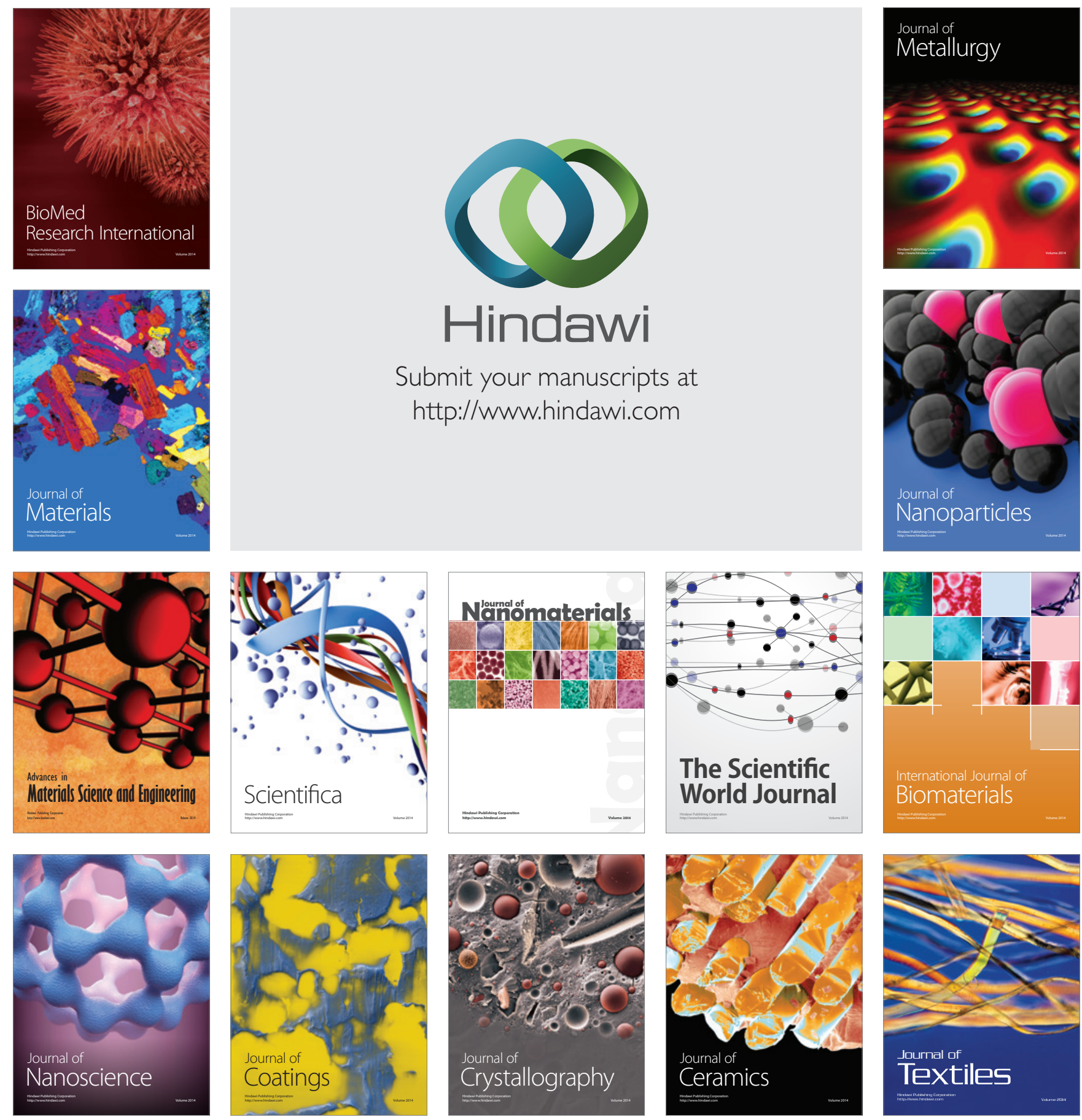